\title{
Analytical Approach for Industrial Microgrid Infeed Peak Power Dimensioning.
}

\author{
Armands Senfelds, Oskars Bormanis, Arturs Paugurs \\ Institute of Industrial Electronics and Electrical Engineering \\ Riga Technical university \\ Riga, Latvia
}

\begin{abstract}
Method of estimating optimal power supply performance parameters with comparison of two different power measurement data analysis methods is introduced. Application of estimating optimal infeed supply converter performance parameters for industrial DC microgrid with multiple DC supplied industrial manipulators and an spot welding process has been analyzed.
\end{abstract}

Keywords - Microgrids Industrial engineering Design optimization

\section{INTRODUCTION}

This paper present insight into approach of existing power profile analysis approach for corresponding dimensioning of main power system interface converter equipment based on production power load data example. Fundamental analytical approach for repetitive power profiles is introduced within Section 2 followed by proposed workflow strategies applying aforementioned analysis in case of several power profile datasets in Section 3. Example application based on real production power profile data has been introduced in Section 4.

Obtained analytical results are presented within Section 5.

The switch from conventional AC to DC power supply infrastructure has become an increasingly discussed topic due to several promising benefits increasing overall energy efficiency potential reduction of the amount of raw materials necessary for energy transmission such as copper and insulation materials and minimizing the power conversion stages on the overall system level as discussed by [1],[2],[3],[4]. DC supply grids also enable more energy efficient adaption of renewable energy sources, such as photovoltaic panels, and energy storage elements being batteries since generation of DC voltage is inherent behavior of such technologies [5]. An application of a DC grid based robot work cell has been discussed as example for analytical power profile research within current paper.

Design of a DC microgrid adapted for operation within existing $\mathrm{AC}$ type power infrastructure requires central main rectifier converter to generate DC voltage from the AC grid. It is crucial to choose an optimal solution for the rectifier unit by its performance parameters to avoid incorrect power supply dimensioning and thus inefficient exploitation. Industrial power electronic converters are designed according to maximum power requirements of the system, however, with a combination of multiple power supply technologies in a single system, such approach may prove resource wasteful. For example, in a system with multiple DC supplied industrial robots, main rectifier unit is designed to supply the combined maximum power peaks of all robots, even when such occurrence is very unlikely. According to [6],[7] industrial robots spend more time in standby than in movement, therefore, it must be considered when designing the system power supply to avoid over-dimensioning.

It is generally known that when applied with load less than $10-20 \%$ of the rated nominal output power converters represent lower efficiency therefore installing a high power main supply unit in a system where the average power significantly below the nominal power of the supply unit power losses are expected due to underutilization of installed equipment. Additionally, this occurs because with increasing the power rating of the supply converter its standby power losses increase as well and make up a larger percentage of the total energy consumption. The proposed analytical methodology can be considered as basis for optimal dimensioning of main supply converters during stage of production plant planning by application of virtual commissioning software as well since energy consumption parameters are planned to be brought into virtual production modelling software tools in near future [5], [8]-[11]. It is to be mentioned that also experimental data of existing process loads can be obtained and considered as basis for analysis in case if extension or modification of existing infrastructure is to be done. Typically energy consumption within production environment is cyclic and repetitive. With access to either measured or simulated energy consumption data assumptions regarding the main supply converter parameters can be made based on defined time cycle according to manufacturing processes.

\section{POWER CONSUMPTION ANALYSIS}

Power consumption analysis approach has been presented under assumption that some data about expected production equipment dynamic electrical load variation has been provided by experimental measurements or numeric simulations. The visual representation of analytical data evaluation has been presented in following

Fig. 1. The data with given fixed sampling frequency $f_{\text {sample }}$ has been obtained for respective time frame length $t_{\mathrm{n}}$. Analysis of input data is based on concept of sliding analysis window being shifted along whole dataset and with variable window width. 


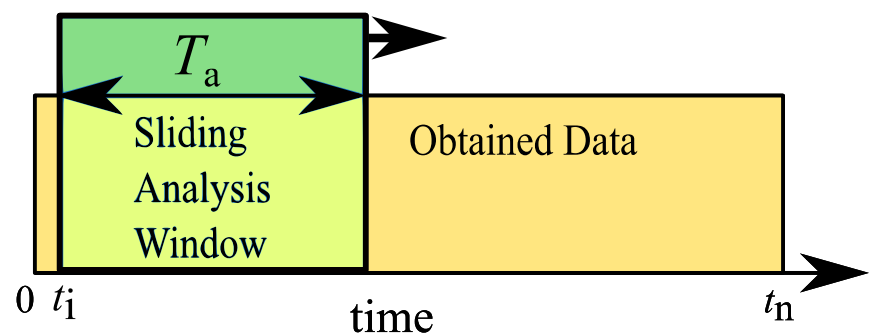

Fig. 1. Visualization of sliding analysis window approach application for power data analysis.

Therefore minimum and maximum sliding window size options can be defined based on following equations (1) and (2).

$$
\begin{aligned}
& \text { 1. } T_{\min }=\frac{1}{f_{\text {sample }}} \\
& T_{\max }=t_{n}
\end{aligned}
$$

The minimum window is defined by applied sampling frequency of data and respective distance between two neighbor values. Maximum window available for analysis is limited by total data sampling time frame. By selecting corresponding time window size $T_{\mathrm{a}}$ to be shifted along data set respective number of samples for instantaneous evaluation within analysis window can be defined according to following equation (3).

$$
n=\frac{T_{a}}{f_{\text {sample }}}, T_{a} \in\left[T_{\min }, T_{\max }\right]
$$

Such number of values is selected for evaluation of average power $P_{\text {avg }}$ within scope of analysis window being shifted according to number of samples $i$ as represented by following equation (4).

$$
P_{\text {avg }}\left(i, T_{a}\right)=\frac{1}{n} \cdot \sum_{i}^{i+n} P_{i}, i \in\left[1, t_{n}-n\right]
$$

The boundaries of initial position $i$ are maintained taking into account selected analysis window sample number $n$ in order to remain within total time frame of initial data characterized by $t_{\mathrm{n}}$. The final analysis result for particular analysis window width being shifted along initial data is determined according to equation (5).

$$
P\left(T_{a}\right)=\max \left(P_{a v g}\left(i, T_{a}\right)\right),
$$

By analysis according to equations characteristic behavior of electrical load maximal instantaneous power requirement can be determined.

\section{APPLICATION STRATEGIES OF POWER CONSUMPTION ANALYSIS}

In case if several electrical process load data sets are available various routines of application of proposed power analysis approach can be derived. The following section present two potential workflow structure concepts based on same initial power profile data sets but different sequence of performed operations. Such routines may be introduced as post processing activities in higher layers of virtual modelling software applications thus presenting supportive information for decision making on selecting suitable electrical component ensuring local power supply functionality.

\section{A. Parallel analysis structure concept}

The visualization of the first concept is presented in Fig. 2. Such approach is based on initial application of power analysis to each available dataset and following combination of obtained

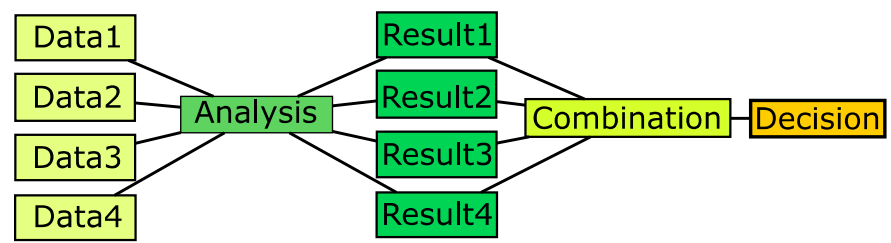

Fig. 2 Visualization of parallel power profile analysis workflow structure.

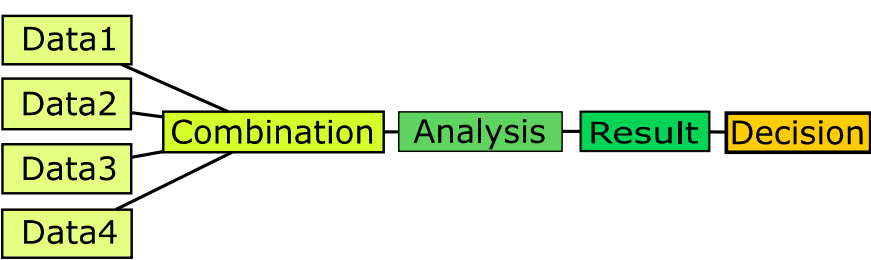

Fig. 3 Visualization of combined power profile analysis workflow structure.

analysis results for final decision making procedure. In this case combination of analysis results is performed by maintaining same time reference axis but adding all maximum power demand values for each load within fixed time window.

\section{B. $\quad$ Combined analysis structure concept}

Another potential workflow structure can be introduced by initial combination of individual power profiles within single time reference maintaining exact location in time and followed analysis procedure applied to such common power profile. Analytical procedure sequence is performed as represented visually in Fig. 3.

\section{VERIFICATION ON PRODUCTION PROCESS POWER DATA}

As measure to verify intended analytical procedure set of electrical power consumption data from real production process has been obtained by means of synchronous logging of power consumption during typical manufacturing process cycle. Efforts of data acquisition during development phase of production infrastructure are of rising importance and computer based simulation models as well as functional models of typical production equipment become interesting topic. The following set of electrical loads has been selected for case example in this paper - set of 4 manipulators with integrated electrical drives and spot welding equipment involved in manufacturing process. Total production cycle for particular process is performed within 110 second time period. Peak power of 4 manipulator devices reach level of $20 \mathrm{~kW}$ range which is significantly lower compared to welding process electrical load reaching level of $200 \mathrm{~kW}$ during short 
pulse wise pattern of $70 \mathrm{~ms}$ duration per each welding point instance. The manipulator with index RB4 is combined with welding equipment and during welding process maintain standby position. Other manipulators are also dedicated to production tools which present power loads of low consumption level and are therefore excluded from this analysis since would not present large influence of power analysis results. Combination of 4 manipulator loads and spot welding equipment are presented in following Fig. 4.
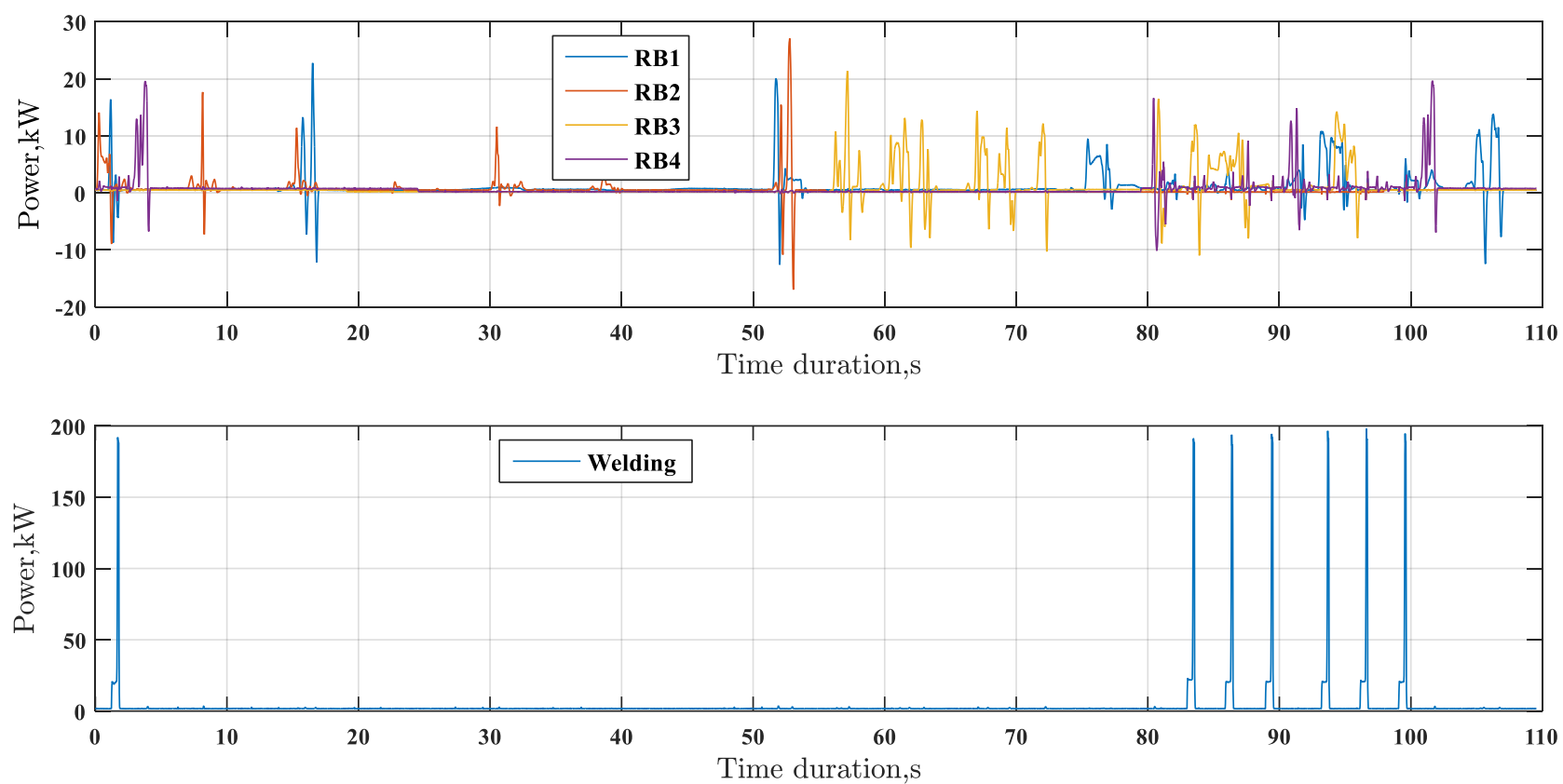

Fig. 4 Example of cyclic production cycle electrical power consumption.

\section{ANALYTICAL RESULTS}

Analytical procedure has been applied on presented power consumption data according to workflows introduced in Section 3. The Fig. 5 present maximum average power analysis results of power profile data of manipulators RB1 to RB4 with highest peak power value presented by RB2 reaching $26 \mathrm{~kW}$.

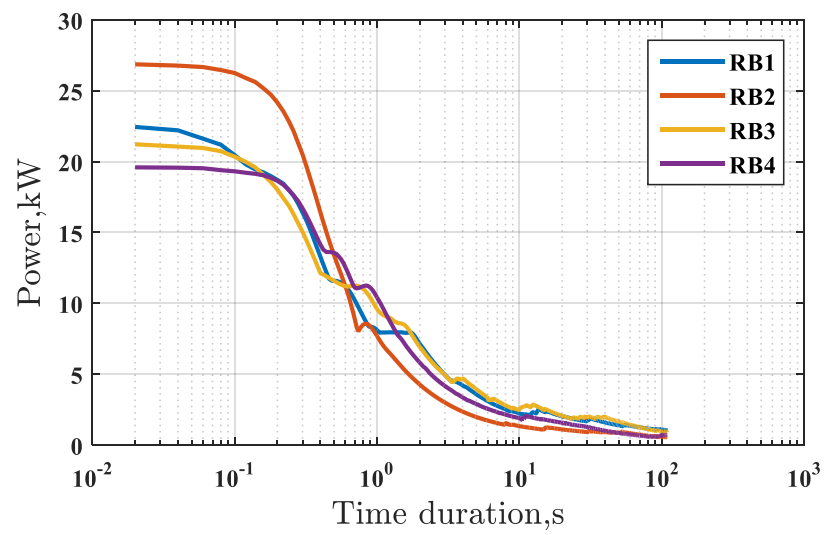

Fig. 5 Power analysis results of 4 manipulator set.

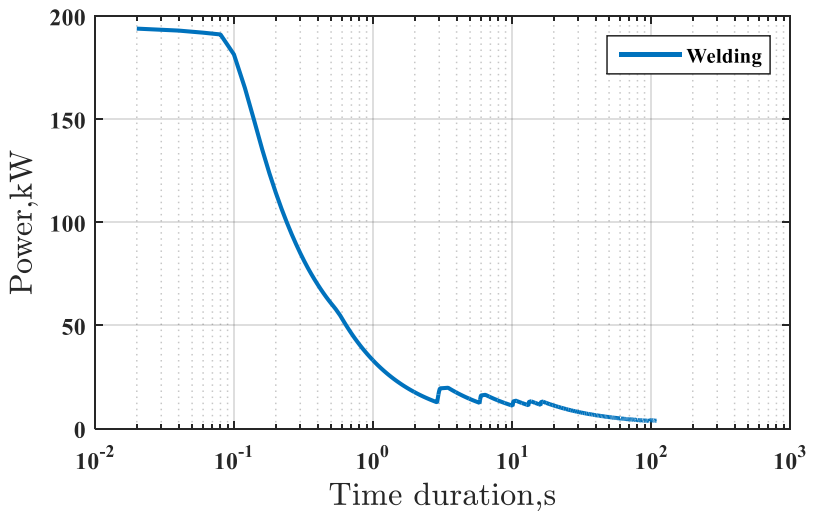

Fig. 6 Power analysis results of welding power profile.

The Fig. 6 represent same analytical procedure results applied to welding load power profile and lead to peak power value of $198 \mathrm{~kW}$. Such data present material for combination of obtained analytical material by summation of peak power of all involved loads during same time window size. Along with parallel analysis structure concept also combined analysis concept structure has been applied by summation of original power profiles based on same time axis leading to total power consumption profile fed into analytical processing. The following Fig. 7 present obtained results by both analytical results and average power consumption of $7 \mathrm{~kW}$ over long term 


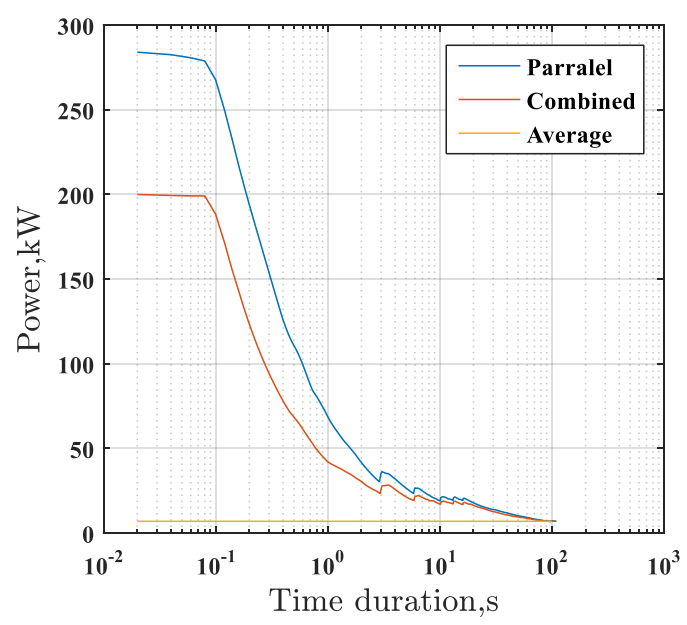

Fig. 7 Comparison of both workflow concept results.

operation. Difference between parallel and combined analysis present value of $80 \mathrm{~kW}$ comparing single values of $280 \mathrm{~kW}$ and $200 \mathrm{~kW}$ allowing to consider approach of parallel analysis leading to over dimensioning since all short term power peaks are combined. Therefore approach of combined power profile analysis would be favorable since coincidence factor of individual peak power present significant influence on system peak power dimensioning. The obtained analytical data present basis for decision making and operational strategy selection regarding power supply solutions covering whole production process including all electrical load elements and their expected operational behavior. An illustrative example of obtained analytical power curve application for main infeed power converter design is presented in Fig. 8 with respect to active frontend (AFE) being selected for full peak power capability or analytical distribution of power demand requirements between reduced nominal power equipment in combination with energy buffer solution for particular production process.

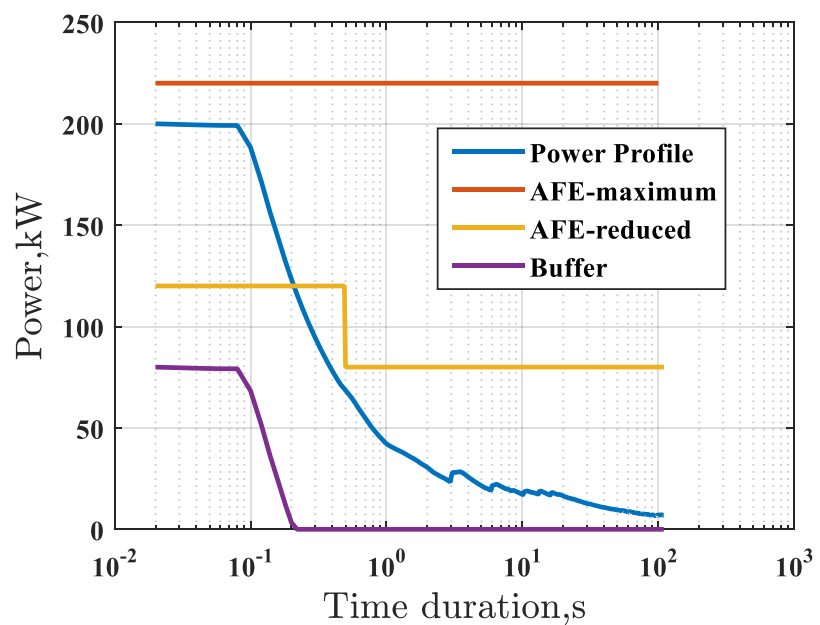

Fig. 8 Example of analytical power demand curve application for infeed dimensioning strategy development.

\section{CONCLUSIONS}

This paper introduce concept of peak power and time related analysis applied to set of industrial production process equipment electrical load data set. Analysis can be carried out according to different workflow strategies leading to results and emphasizing necessity of information about peak power coincidence during cycle time. Potential application of analytical results are presented regarding decision making procedure for suitable electrical power supply equipment intended for local production process electrical supply needs.

\section{ACKNOWLEDGEMENTS}

This research is supported by Latvian National Research Programme project LATENERGI.

\section{REFERENCES}

[1] R. Weiss, "Energy Efficient Low-Voltage DC-Grids for Commercial Buildings," pp. 154-158, 2015.

[2] P. van Willigenburg, J. Woudstra, P. van Duijsen, B. Groenewald, and H. Stokman, "Second step to full DC-potential: DC grid efficiency for Home Owners Associations," 2015 Int. Conf. Domest. Use Energy, pp. 101-108, 2015.

[3] Y. Cao, B. Yang, and J. Zhuang, "Research on a novel DC / DC transformer and its control strategy for DC grid-connected renewable energy," no. Mmc.

[4] J. Woudstra, P. van Willigenburg, B. Groenewald, H. Stokman, S. De Jonge, and S. Willems, "Direct current distribution grids and the road to its full potential," ... Commer. Use ..., pp. 2-7, 2013.

[5] B. Wunder, J. Kaiser, F. Fersterra, L. Ott, Y. Han, and M. März "Energy Distribution with DC Microgrids in Commercial Buildings with Power Electronics," pp. 425-430, 2015.

[6] D. Meike and L. Ribickis, "Recuperated energy savings potential and approaches in industrial robotics," IEEE Int. Conf. Autom. Sci. Eng., pp. 299-303, 2011.

[7] D. Meike, M. Pellicciari, and G. Berselli, "Energy Efficient Use of Multirobot Production Lines in the Automotive Industry: Detailed System Modeling and Optimization," Autom. Sci. Eng. IEEE Trans., vol. 11, no. 3, pp. $798-809,2013$.

[8] R. Neugebauer, F. Pürzel, A. Schreiber, and T. Riedel, "Virtual reality-aided planning for energy-autonomous factories," IEEE Int. Conf. Ind. Informatics, pp. 250-254, 2011.

[9] O. Bormanis, "Development of Energy Consumption Model for Virtual Commissioning Software," pp. 1-4.

[10] A. Vergnano, C. Thorstensson, B. Lennartson, P. Falkman, M. Pellicciari, C. Yuan, S. Biller, and F. Leali, "Embedding detailed robot energy optimization into high-level scheduling," 2010 IEEE Int. Conf. Autom. Sci. Eng. CASE 2010, pp. 386-392, 2010.

[11] A. Vergnano, C. Thorstensson, B. Lennartson, P. Falkman, M. Pellicciari, F. Leali, and S. Biller, "Modeling and optimization of energy consumption in cooperative multi-robot systems," Tase, vol. 9, no. 2, pp. 423-428, 2012.

Armands Senfelds received B.Sc.eng. of Riga Technical University, Latvia and M.Sc of RWTH Aachen University, Germany at 2009 and 2012, respectively at field of Electrical Power engineering. He is a $\mathrm{PhD}$ student and researcher at Riga Technical university, Institute of Industrial electronics and Electrical engineering. His research interests include design and control of power electronic equipment, electrical drives and electrical mobility.

Oskars Bormanis received B.Sc.eng. and M.Sc.eng. in electrical engineering from Riga Technical University, Latvia in 2014 and 2015. Since 2011 he is employed by Institute of industrial electronics and electrical engineering of RTU. Main research interests include industrial robots, industrial DC grids. $\mathrm{He}$ is a member of IEEE Industry Applications Society.

Arturs Paugurs received B.Sc.eng. and M.Sc.eng of Riga Technical University, Latvia in the field of Electrical Engineering. Practised in Daimler AG, (Sindelfingen, Germany) in a project regarding energy efficiency optimization methods in robotic systems.He is a member of IEEE Industry Applications Society and a member of RTU Student Branch. 